\title{
Novel Zero-Heat-Flux Deep Body Temperature Measurement in Lower Extremity Vascular and Cardiac Surgery
}

\section{Mäkinen, Marja-Tellervo}

2016-08

Mäkinen , M-T , Pesonen , A , Jousela , I , Paivarinta , J , Poikajärvi , S , Albäck , A , Salminen, U-S \& Pesonen, E 2016 , ' Novel Zero-Heat-Flux Deep Body Temperature Measurement in Lower Extremity Vascular and Cardiac Surgery ', Journal of Cardiothoracic and Vascular Anesthesia , vol. 30 , no. 4 , pp. 973-978 . https://doi.org/10.1053/j.jvca.2016.03.141

http://hdl.handle.net/10138/225133

https://doi.org/10.1053/j.jvca.2016.03.141

publishedVersion

Downloaded from Helda, University of Helsinki institutional repository.

This is an electronic reprint of the original article.

This reprint may differ from the original in pagination and typographic detail.

Please cite the original version. 


\title{
Novel Zero-Heat-Flux Deep Body Temperature Measurement in Lower Extremity Vascular and Cardiac Surgery
}

\author{
Marja-Tellervo Mäkinen, $\mathrm{MD}, \mathrm{PhD}$,* Anne Pesonen, $\mathrm{MD}, \mathrm{PhD}$, Irma Jousela, $\mathrm{MD}, \mathrm{PhD}$,* \\ Janne Päivärinta, RN, ${ }^{*}$ Satu Poikajärvi, RN, MNSc, ${ }^{*}$ Anders Albäck, MD, PhD, $\dagger$ \\ Ulla-Stina Salminen, MD, PhD, $\neq$ and Eero Pesonen, MD*
}

Objective: The aim of this study was to compare deep body temperature obtained using a novel noninvasive continuous zero-heat-flux temperature measurement system with core temperatures obtained using conventional methods.

Design: A prospective, observational study.

Setting: Operating room of a university hospital.

Participants: The study comprised 15 patients undergoing vascular surgery of the lower extremities and 15 patients undergoing cardiac surgery with cardiopulmonary bypass.

Interventions: Zero-heat-flux thermometry on the forehead and standard core temperature measurements.

Measurements and Main Results: Body temperature was measured using a new thermometry system (SpotOn; 3M, St. Paul, MN) on the forehead and with conventional methods in the esophagus during vascular surgery $(n=$ 15), and in the nasopharynx and pulmonary artery during cardiac surgery $(n=15)$. The agreement between SpotOn and the conventional methods was assessed using the Bland-Altman random-effects approach for repeated measures. The mean difference between SpotOn and the

A NESTHETIZED PATIENTS GENERALLY become hypothermic during surgery if control of body temperature is neglected. ${ }^{1-3}$ Even mild, inadvertent perioperative hypothermia leads to increased blood loss and transfusions, ${ }^{1,4}$ postoperative wound infections, ${ }^{2,5}$ cardiovascular incidents, ${ }^{6}$ prolonged hospitalization, ${ }^{2,7}$ and increased mortality. ${ }^{8,9}$ Thus, accurate monitoring of body temperature is mandatory to maintain the heat balance of surgical patients. In addition, continuous measurement of body temperature enhances detection of malignant hyperthermia, ${ }^{10}$ fever, or eventual overheating. ${ }^{11}$ Of special concern are surgeries with large exposed body areas, procedures with induced hyperthermia or hypothermia, or control of brain temperature during rewarming from hypothermia in cardiac surgery. ${ }^{12}$

Most adequate core temperature measurement sites (eg, pulmonary artery [PA], esophagus, nasopharynx, or tympanum) are somewhat invasive, at times unobtainable, and carry the risk of various complications. More intermediate points (eg, urinary bladder or rectum) are less accurate and also inconvenient for unanesthetized patients. Less-invasive points (eg, axilla, mouth, or temporal artery) are not applicable for continuous measurement. ${ }^{7,13}$ An ideal perioperative core temperature measurement technique should be reliable, accurate, and noninvasive; provide continuous display; and enable online automatic data recording.

In 1971, Fox and Solman introduced a new method to measure deep body temperature superficially from the intact skin. ${ }^{14}$ The technique was described as bringing deep body temperature to the surface, where an efficient insulator on the skin created a region of zero heat flow from the core to the shell of the body. The temperatures of the skin and the deep tissue were assumed to be equal when heat flow between the skin and esophageal temperature during vascular surgery was $+0.08 \mathrm{C}\left(95 \%\right.$ limit of agreement -0.25 to $\left.+0.40^{\circ} \mathrm{C}\right)$. During cardiac surgery, during off $\mathrm{CPB}$, the mean difference between SpotOn and the pulmonary arterial temperature was $-0.05 \mathrm{C}(95 \%$ limits of agreement -0.56 to $+0.47 \mathrm{C})$. Throughout cardiac surgery (on and off $\mathrm{CPB}$ ), the mean difference between SpotOn and the nasopharyngeal temperature was $-0.12 \mathrm{C}(95 \%$ limits of agreement -0.94 to $+0.71^{\circ} \mathrm{C}$ ). Poor agreement between the SpotOn and nasopharyngeal temperatures was detected in hypothermia below approximately $32^{\circ} \mathrm{C}$.

Conclusions: According to this preliminary study, the deep body temperature measured using the zero-heat-flux system was in good agreement with standard core temperatures during lower extremity vascular and cardiac surgery. However, agreement was questionable during hypothermia below $32 \mathrm{C}$.

(c) 2016 Elsevier Inc. All rights reserved.

KEY WORDS: body temperature, noninvasive, monitoring, thermometer, zero-heat-flux, core temperature

deep tissue was discontinued (ie, heat flow was 0 ). Indefinite equilibrium time of the system to reach the initial deep temperature reading was reduced to approximately 20 minutes by adding an electrical servo-controlled heater to the probe. The system was tested in awake patients under various circumstances ${ }^{15}$ and later during surgery with general anesthesia. $^{16}$ Thereafter, the technique was developed ${ }^{17-19}$ and applied in intensive care, ${ }^{20}$ during whole-body hyperthermia, ${ }^{21}$ hypothermic cardiopulmonary bypass $(\mathrm{CPB}),{ }^{22}$ and in postanesthesia care. ${ }^{23}$ However, because of drawbacks of the until recently available devices (eg, long equilibrium time $\mathrm{e}^{19,22}$ and nondisposable patient electrodes), clinical application of the zero-heat-flux method has remained limited.

Recently, a new, improved zero-heat-flow deep temperature monitoring system, with an equilibrium time of 3 minutes to the start temperature, a lightweight disposable patient probe,

From the *Division of Anaesthesiology, Department of Anaesthesiology, Intensive Care and Pain Medicine; †Abdominal Center, Department of Vascular Surgery, Meilahti Hospital, Helsinki, Finland; and $\$$ Heart and Lung Center; Department of Cardiac Surgery, University of Helsinki and Helsinki University Hospital, Helsinki, Finland.

The SpotOn temperature monitoring system was supplied for the study by 3M, St. Paul, MN. M.T. Mäkinen is a member of an advisory board of $3 M$ for patient temperature management. This study was investigator initiated.

Address reprint requests to Marja-Tellervo Mäkinen, $M D, P h D$, Ulvilantie 11a A 11,00350 Helsinki, Finland.E-mail: makinentelle@ gmail.com

(C) 2016 Elsevier Inc. All rights reserved.

1053-0770/2601-0001\$36.00/0

http://dx.doi.org/10.1053/j.jvca.2016.03.141 
continuous temperature display, and an option to attach the system to automatic data recording, was developed (SpotOn; $3 \mathrm{M}$, St. Paul, MN). The aim of this study was to evaluate whether the noninvasive deep body temperature measured with this new device was reliable compared with standard core temperature measurements to represent core temperature during 2 distinct types of surgery (ie, lower extremity vascular surgery and cardiac surgery with $\mathrm{CPB}$ ).

\section{METHODS}

\section{Patients}

This prospective, observational study (DNro 142/13/03/02/ 2013) was approved by the ethics committee of Helsinki University Hospital on May 15, 2013 (Chairperson Dr. L.M. Aaltonen). After written informed consent from the patients, the data were collected between September and December 2013.

The study comprised 2 separate patient series. First, 15 consecutive patients scheduled for vascular surgery of the lower extremities were enrolled. Of those, 13 patients underwent revascularization of lower limb arteries because of arteriosclerotic disease, and 2 patients underwent reconstruction of femoral or popliteal artery aneurysms due to etiology different from arteriosclerosis. Second, 15 patients undergoing cardiac surgery with CPB for coronary artery bypass grafting (7 patients), aortic valve replacement (6 patients), or reconstruction of the ascending aorta ( 2 patients) were recruited.

\section{Anesthesia and Intraoperative Care}

In the vascular surgery patients, general anesthesia was induced with fentanyl, propofol, and rocuronium and was maintained with sevoflurane or desflurane, supplemented with increments of fentanyl and rocuronium as needed. In the cardiac surgery patients, anesthesia was induced with intravenous fentanyl, alfentanil or sufentanil, and propofol or etomidate and rocuronium and was maintained with sevoflurane and opioid infusion, supplemented with rocuronium as needed. The patients were ventilated with a Datex-Ohmeda S/5 anesthesia machine (GE Healthcare, Helsinki, Finland). In the cardiac surgery patients, CPB was conducted using moderate hypothermia (nasopharyngeal temperature $32-34^{\circ} \mathrm{C}$ ), a membrane oxygenator, and a roller pump. Cold blood-crystalloid cardioplegia solution was used for myocardial protection. During CPB, the pump flow rate was $2.4 \mathrm{~L} / \mathrm{min} / \mathrm{m}^{2}$, and perfusion pressure was maintained between 50 and $80 \mathrm{mmHg}$. At the end of the surgeries, the vascular surgery patients were extubated and the cardiac patients were transferred to the intensive care unit.

Respiratory and anesthetic gas concentrations, online spirometry, blood oxygen saturation, electrocardiogram, invasive blood pressures, E-Entropy (GE Healthcare), and body temperatures were displayed on the Datex-Ohmeda S/5 Anesthesia Monitor and saved in the automatic anesthesia recording system (Caresuite Anesthesia Manager 8.0; Picis Inc., Wakefield, MA). In cardiac patients, central venous and PA pressures and cardiac output were recorded, and esophageal echocardiography $(\mathrm{ECHO})$ was performed.

\section{Temperature Monitoring and Maintenance of Body Temperature}

In all patients, on arrival to the operating room, a SpotOn skin probe (Sensor Model 360), $41 \mathrm{~mm}$ in diameter and 5-mm thick, was fixed on the patient's forehead above the right eyebrow, and laterally close to the SpotOn, a skin temperature probe (Mon-a-therm skin temperature probe 400 Series TM; Covidien, Boulder, $\mathrm{CO}$ ) was placed; both devices are disposable and were adhered with self-adhesive tape. The SpotOn probe was connected to the SpotOn thermometry device (SpotOn Temperature Monitoring System Model 370). ${ }^{24}$ This was attached further to the anesthesia monitor for continuous display and data saving. After intubation, a core temperature probe (Mon-a-therm general purpose temperature probe 400 Series TM; Covidien) was inserted into the lower esophagus (40 $\mathrm{cm}$ from the nose) in the vascular surgery patients and in the nasopharynx in the cardiac surgery patients. In both patient groups a urinary bladder temperature probe (Mon-a-therm Foley with temperature sensor 400 Series TM; Covidien) was placed, and in the cardiac surgery patients a PA temperature probe (Swan-Ganz; Edwards Lifesciences, Irvine, CA) also was inserted.

Intravenous fluids either were prewarmed or administered through an online warming system (Ranger Blood/Fluid Warming Unit, model 245 ; $3 \mathrm{M}$ ). In vascular surgery patients, an upper body forced-air warming blanket (Bair Hugger; 3M) was applied, and in cardiac surgery patients a resistive underbody warming mattress (Inditherm, Rotherham, UK) was used. During the cooling phase of $\mathrm{CPB}$ in cardiac surgery patients, moderate hypothermia of 32 to $34{ }^{\circ} \mathrm{C}$ nasopharyngeal temperature was induced, except in 1 patient undergoing reconstruction of the aortic arch. In the latter patient, hypothermia to $26^{\circ} \mathrm{C}$ was induced. Before weaning from $\mathrm{CPB}$, the patients' nasopharyngeal temperature was rewarmed to $36^{\circ} \mathrm{C}$.

\section{Data Processing and Statistics}

All temperatures were saved online in the hospital's database, from which they can be retrieved at chosen intervals. The authors decided to use an interval of 5 minutes, which they considered long enough to detect a relevant change of temperature between 2 consecutive time points. MedCalc statistical software (MedCalc Software, Ostend, Belgium) was used for statistical analyses. Mean values are used in Table 1, which details demographic and surgical patient data, and in Figures 1 and 3 , which illustrate temperature changes as a function of time.

The primary endpoint of the study was agreement of SpotOn deep body temperature with conventional core temperature measurements. At the initiation of the study, there were no clinical reports on the SpotOn temperature measurement system for calculation of power analysis. To assess for agreement between SpotOn and conventional methods of core temperature measurement, the authors used the Bland-Altman random-effects approach for data of repeated measures. ${ }^{25}$ SpotOn was compared with the esophageal temperature in vascular surgery and with the PA temperature in cardiac surgery. In the latter, the period of $\mathrm{CPB}$ was excluded from the analysis because there was no PA blood flow or it was significantly reduced at that time. To gain information on the 
Table 1. Patient Characteristics and Surgical Data

\begin{tabular}{lcc}
\hline & Vascular Surgery & Cardiac Surgery \\
\hline Number of patients & 15 & 15 \\
Age (year) & $64 \pm 13$ & $68 \pm 9$ \\
Height $(\mathrm{cm})$ & $171 \pm 10$ & $170 \pm 12$ \\
Weight $(\mathrm{kg})$ & $77 \pm 17$ & $75 \pm 14$ \\
BMI $\left(\mathrm{kg} / \mathrm{m}^{2}\right)$ & $26 \pm 4$ & $26 \pm 4$ \\
Sex $(\mathrm{male} / \mathrm{female})$ & $11 / 4$ & $10 / 5$ \\
Duration of anesthesia $(\mathrm{min})$ & $295 \pm 122$ & $346 \pm 75$ \\
Duration of surgery $(\mathrm{min})$ & $220 \pm 111$ & $264 \pm 74$ \\
Duration of CPB (min) & - & $118 \pm 41$ \\
\hline
\end{tabular}

NOTE. Values are presented as mean \pm standard deviation.

accuracy of SpotOn temperature measurement during CPB, it also was compared with the nasopharyngeal temperature throughout cardiac surgery (ie, also during $\mathrm{CPB}$ ). Mean differences and $95 \%$ limits of agreement were calculated and a graphic display of differences versus means was generated. The limits of agreement were calculated as the mean bias \pm 2 standard deviations. A difference of $\pm 0.5^{\circ} \mathrm{C}$ between 2 temperature measurement methods was defined as an acceptable agreement. $^{26}$

\section{RESULTS}

Temperature data were obtained from all the consecutively enrolled 30 patients. Patient characteristics and surgical data of both patient populations are presented as mean \pm standard deviation or numbers in Table 1 .

\section{Vascular Surgery}

At the induction of anesthesia, the SpotOn and skin temperatures were equilibrated to the initial values. The esophageal temperature reading was on display shortly after intubation. The vesical temperature was available later during routine preparations (see Fig 1). The SpotOn and esophageal temperatures paralleled each other throughout the procedure, the former being marginally, but constantly, higher. In BlandAltman analysis, the mean difference (ie, bias) between SpotOn

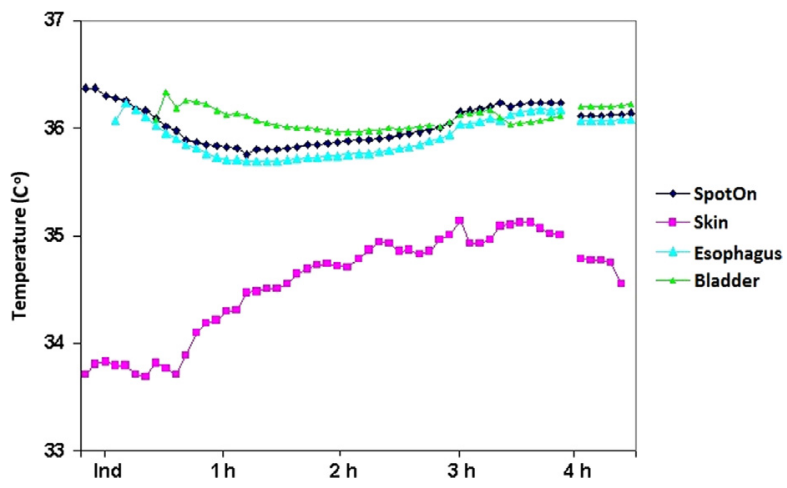

Fig 1. SpotOn, distal esophageal, urinary bladder, and forehead skin (skin) mean temperatures of the vascular surgery patients at 5minute intervals. Each temperature point was included in the illustration when $\mathbf{1 0}$ or more measurements were complete at that time. Ind, induction of anesthesia; $1 \mathrm{~h}, 2 \mathrm{~h}, 3 \mathrm{~h}$, and $4 \mathrm{~h}$, hours after induction. and the esophageal temperature was $+0.08^{\circ} \mathrm{C}$, and the $95 \%$ limit of agreement was -0.25 to $+0.40^{\circ} \mathrm{C}$ (see Fig 2).

The temporal course of the bladder temperature deviated from the other deep temperature measurements (see Fig 1). At the beginning it was higher, and it then steadily declined and was at a level similar to the SpotOn and esophageal temperatures after 2 hours during the procedure. The forehead skin temperature was approximately $3^{\circ} \mathrm{C}$ lower than the SpotOn and esophageal temperatures at anesthesia induction (see Fig 1). Thereafter, the skin temperature steadily increased but remained at least $1^{\circ} \mathrm{C}$ lower than the SpotOn and other deep temperatures until the end of the procedure.

\section{Cardiac Surgery}

The SpotOn and skin temperatures were equilibrated to the initial values at the induction of anesthesia (see Fig 3). Nasopharyngeal, PA, and vesical temperatures were ready on the display later during the preparations (eg, PA catheterization and esophageal echocardiography). The SpotOn and both core temperatures (nasopharyngeal and PA) paralleled closely to each other both before and after CPB. When the patient was off $\mathrm{CBP}$, the mean difference (bias) in the Bland-Altman analysis between SpotOn and PA was $-0.05^{\circ} \mathrm{C}$ and the $95 \%$ limits of agreement was -0.56 to $+0.47^{\circ} \mathrm{C}$ (see Fig 4).

During $\mathrm{CPB}$, the PA temperature was substantially lower than the SpotOn or nasopharyngeal temperature (see Fig 3). During $\mathrm{CPB}$, both during cooling and rewarming, the SpotOn and nasopharyngeal temperatures paralleled each other, only excluding the lowest temperature, which was around $32^{\circ} \mathrm{C}$. In Bland-Altman analysis, the mean difference (bias) between SpotOn and nasopharyngeal temperatures during off-CPB was $-0.10^{\circ} \mathrm{C}$ and the $95 \%$ limit of agreement was -0.69 to $+0.49^{\circ} \mathrm{C}$ (see Fig 5). During CPB, the mean difference (bias) was $0.14^{\circ} \mathrm{C}$, and the $95 \%$ limit of agreement was -1.23 to $+0.94^{\circ} \mathrm{C}$. During the entire study period, the mean difference (bias) between the SpotOn and nasopharyngeal temperatures was $-0.12^{\circ} \mathrm{C}$, and the $95 \%$ limit of agreement was -0.94 to $+0.71^{\circ} \mathrm{C}$.

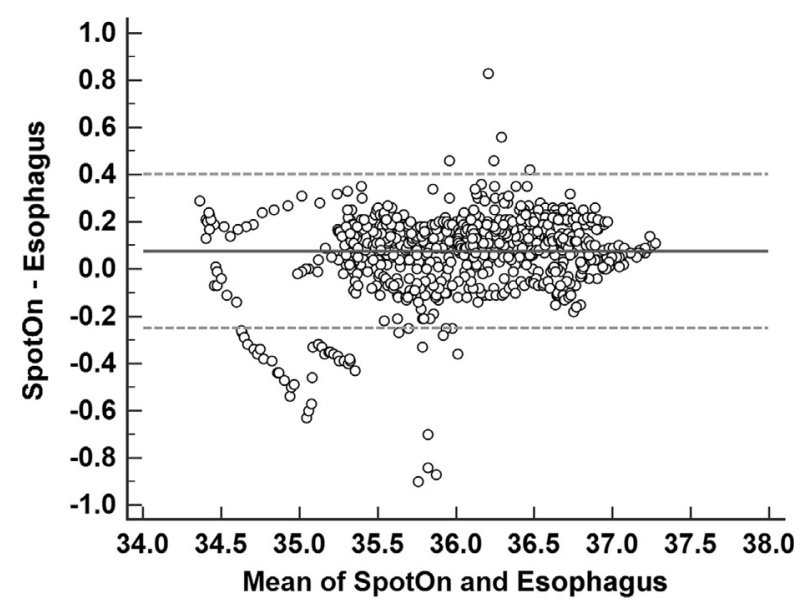

Fig 2. Bland-Altman plot between the SpotOn and distal esophageal (Eso) temperatures of the vascular surgery patients. 


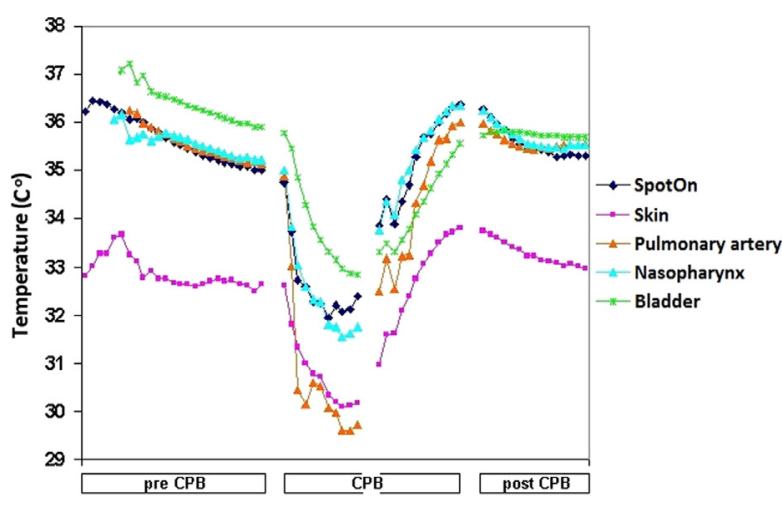

Fig 3. SpotOn, pulmonary artery, nasopharynx, urinary bladder, and forehead skin (skin) mean temperatures of cardiac surgical patients before (pre-CPB), during (CPB), and after CPB (post-CPB) at 5-minute intervals. Each temperature point was included in the illustration when 10 or more measurements were complete at that time.

Of note, in 1 patient, hypothermia was induced to $26^{\circ} \mathrm{C}$. In this patient, at the lowest temperature levels the SpotOn measurement gave up to $2^{\circ} \mathrm{C}$ higher values than the corresponding nasopharyngeal temperature.

The bladder temperature was approximately $1{ }^{\circ} \mathrm{C}$ higher than the nasopharyngeal, $\mathrm{PA}$, or SpotOn temperature before $\mathrm{CPB}$ (see Fig 3). During CPB, the bladder temperature lagged behind, during cooling it was higher, and during rewarming it was lower than the other deep temperatures. After CPB, bladder temperature was at a similar level with the SpotOn, nasopharyngeal, and PA temperatures. The forehead skin temperature was 2 -to- $3^{\circ} \mathrm{C}$ lower than the deep body temperature measurements throughout the study period (see Fig 3).

\section{DISCUSSION}

In this study, the authors evaluated the novel, noninvasive zero-heat-flux deep forehead temperature against conventionally measured core temperatures by presenting graphically the temporal course of the temperatures throughout the procedures (see Figs 1 and 3). Agreement of the temperatures measured simultaneously using different methods of thermometry was

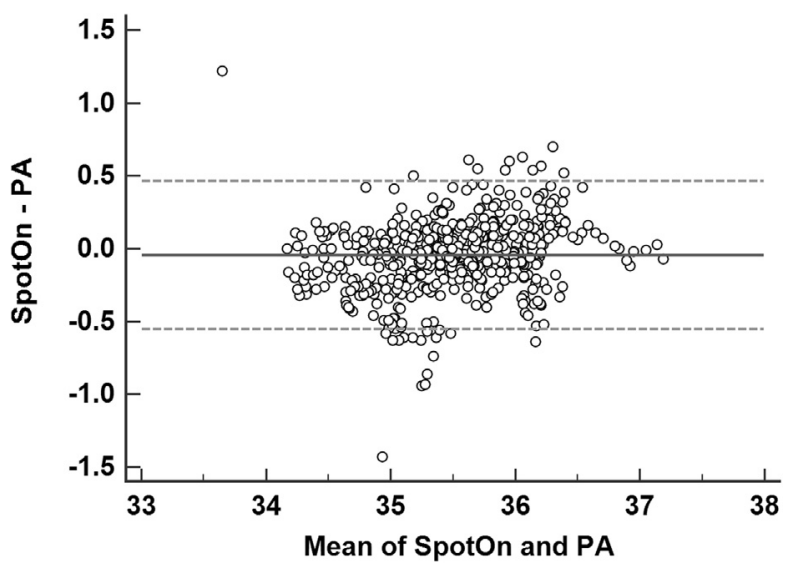

Fig 4. Bland-Altman plot between the SpotOn and pulmonary artery (PA) temperatures of the cardiac surgery patients, when off CPB.

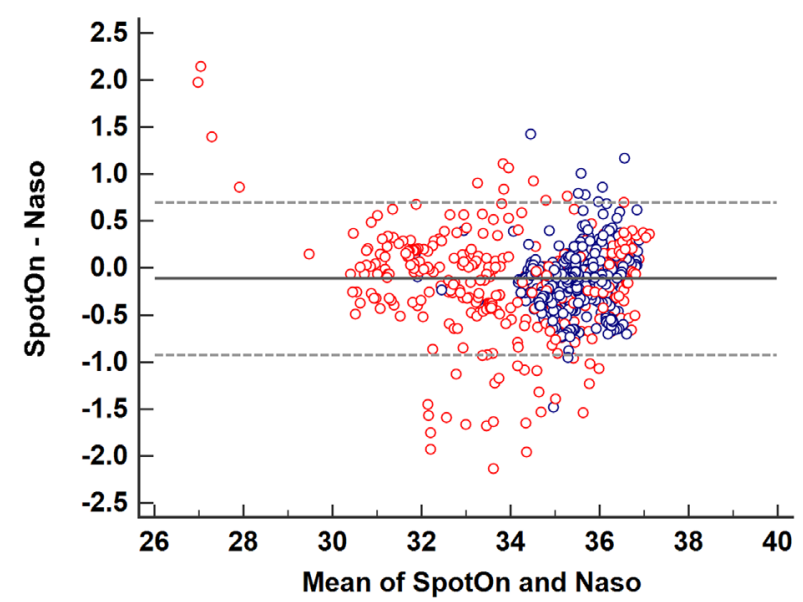

Fig 5. Bland-Altman plot between the SpotOn and nasopharyngeal (Naso) temperatures of the cardiac surgery patients during the entire study period, off-CPB (blue circles) and during CPB (red circles).

assessed using Bland-Altman scatter plot analysis. To get a more versatile picture of the feasibility of the novel method, the authors included in the study 2 types of surgery that differed from each other in terms of temperature management and temperature measurement sites. During on-pump cardiac surgery, the use of CPB enables enhanced extraction (cooling) and delivery (rewarming) of heat via the bloodstream, resulting in rapid and major changes of the core temperature. Vascular surgery, on the other hand, typically is long-lasting with a large uncovered body surface area. In the latter, body heat may be controlled and hypothermia counteracted only by external warming of a limited skin area and by warming the intravenous fluids.

During vascular surgery, the SpotOn temperature closely followed the esophageal temperature, and the agreement between the methods was good, with a mean bias of $+0.08^{\circ} \mathrm{C}$ and a $95 \%$ limit of agreement of -0.25 to $+0.40{ }^{\circ} \mathrm{C}$ (see Fig 2). The agreement was better than the bias of 0.2 or $0.5^{\circ} \mathrm{C}$ between deep body temperatures measured at the forehead or sternum and esophageal temperature in previous studies in which a former Japanese zero-heat-flux thermometry device (Coretemp; Terumo Corp, Tokyo, Japan) was applied during general anesthesia in patients undergoing gynecologic surgery. ${ }^{27,28}$ Recently, the $3 \mathrm{M}$ SpotOn temperature was compared with nasopharyngeal and sublingual temperatures measured conventionally at 3 single time points during gynecologic and trauma surgery. ${ }^{29}$ Using Bland-Altman analysis, the bias between SpotOn and nasopharyngeal temperature $\left(0.07^{\circ} \mathrm{C}\right)$ was similar to the results of the study presented here.

In this study, the agreement of SpotOn with the PA temperature in cardiac surgery $\left(-0.05^{\circ} \mathrm{C}\right.$ bias and 0.56 to $+0.47^{\circ} \mathrm{C}, 95 \%$ limits of agreement; see Fig 4) was approximately as good as the agreement with the esophageal temperature in vascular surgery, but it was better than the recently reported corresponding agreement of SpotOn temperature with PA temperature for which a prototype of the SpotOn system was evaluated. ${ }^{30}$ The results of the present study with the SpotOn device were substantially different from the results 
obtained with a deep tissue temperature device in cardiac surgery. Using the latter device, the zero-heat-flow temperature lagged behind both nasopharyngeal and PA temperatures during cooling and rewarming phases of $\mathrm{CPB} .{ }^{31,32}$ On the other hand, the difference may have been due to deeper hypothermia of less than $20^{\circ} \mathrm{C}$ in the studies applying the Terumo device. In addition, the authors of the study presented here detected poor agreement between the SpotOn and nasopharyngeal temperatures at temperatures below $32^{\circ} \mathrm{C}$ in the patient undergoing deeper hypothermia.

Because PA flow is reduced substantially or nonexistent during $\mathrm{CPB}$, it is not possible to compare SpotOn with the PA temperature reliably at that time. In addition, cold cardioplegia solution may affect the temperature at the site of the heart and great vessels. To gain some idea of the accuracy of the novel system during CPB, the authors compared the SpotOn with the nasopharyngeal temperature. Furthermore, the nasopharyngeal temperature traditionally is used as an estimate of the brain temperature in cardiac surgery. In the study presented here, the agreement between the methods was quite good, with a $95 \%$ limit of agreement of -0.69 to +0.49 for off-CPB (Fig 5). During CPB, the agreement clearly was weaker, with a $95 \%$ limit of agreement of -0.94 to +1.23 . Furthermore, in the patient whose hypothermia was lowered to $26^{\circ} \mathrm{C}$, SpotOn clearly gave higher values than the nasopharyngeal temperature at the lowest temperature levels. In a recent evaluation of the SpotOn system, using a mannequin, $28^{\circ} \mathrm{C}$ was reported as the lower measurement limit. ${ }^{33}$

The principal difference between zero-heat-flux SpotOn thermometry and conventional means of core body temperature measurement is that the probe in the latter method directly detects the local tissue temperature. The SpotOn temperature measurement, on the other hand, is based on the achievement of equilibrium between the temperature of the insulated skin and the deeper tissues. Thus, it is important to rule out the effect of artifacts that might interfere with the zero-heat-flux measurements. In this study, SpotOn and skin temperature probes were side-by-side at the forehead. During vascular surgery, forced-air warming on top of the upper torso and the head of the patient was applied, whereas during cardiac surgery a warming mattress was placed under the patient. At the beginning of vascular surgery, the forehead skin temperature was almost $3^{\circ} \mathrm{C}$ lower than the SpotOn and esophageal temperatures (see Fig 1). Whereas the deep temperatures decreased by approximately $1{ }^{\circ} \mathrm{C}$ during vascular surgery, the skin temperature steadily increased and at the end of surgery it was only approximately $1.5^{\circ} \mathrm{C}$ lower than the SpotOn and esophageal temperature. Throughout cardiac surgery, the forehead skin temperature deviated by $1-$ to $-2.5^{\circ} \mathrm{C}$ from the SpotOn and nasopharyngeal temperatures (see Fig 3). First, the data convincingly showed that SpotOn did not measure skin temperature. In this respect, these results were consistent with the recent findings in cardiac surgery. ${ }^{30}$ Second, unlike skin temperature, the SpotOn temperature seemed not to be influenced by local warming.

Placement of the esophageal ECHO probe may interfere with nasopharyngeal or esophageal temperature monitoring and cannot be used in awake patients. In elective surgery a urinary bladder catheter is inserted only after the patient is anesthetized. Furthermore, the bladder temperature lags behind rapid changes $^{19,31}$ and might depend on the amount of urinary excretion. ${ }^{34}$ In the study presented here, bladder temperature deviated from the primary core temperatures, considered to indicate heart and brain heat balance, at the beginning of the surgeries and during rapid changes during CPB. Thus, there was a danger that when the patient's temperature was cooling, the bladder temperature overestimate and during rewarming underestimate the actual core temperature. SpotOn offers a noninvasive method of core temperature measurement in clinical circumstances in which invasive methods cannot be applied.

A major weakness of this study was that the patient numbers in both the cardiac and vascular surgery groups (ie, 15 patients in each) were relatively small. However, the authors believe that the temporal course of body temperatures would not have been different in a larger number of patients. Furthermore, the results of the Bland-Altman analyses were well in line with the conclusions that can be drawn from the comparison of the temporal profiles of temperature changes. Even with the current patient numbers, the authors found good agreement of SpotOn with both esophageal and nasopharyngeal temperatures and the PA temperature off CPB. The major strength of the study was the automated, continuous, online temperature recording, which enabled a dynamic approach to evaluate the interrelationship of several simultaneous temperature measurements as a function of time. The authors' decision to analyze the measurements at an interval as long as 5 minutes ensured that, instead of replicating practically the same measurements within a short time interval, potential changes of body temperatures presumably had sufficiently time to occur. This gave confidence to the fairly narrow limits of agreement found in this study.

Based on the present preliminary data, deep body zero-heatflux temperature measured with the novel SpotOn system was in good agreement with esophageal and PA temperatures above $34^{\circ} \mathrm{C}$ and the nasopharyngeal core temperatures above $32^{\circ} \mathrm{C}$. Importantly, however, poor agreement between the SpotOn and nasopharyngeal temperatures below $32^{\circ} \mathrm{C}$ was observed during CPB. This may be a significant limitation of the SpotOn device when applying it during deep hypothermia in cardiac surgery.

\section{REFERENCES}

1. Bock M, Muller J, Bach A, et al: Effects of preinduction and intraoperative warming during major laparotomy. Br J Anaesth 80:159-163, 1998

2. Kurz A, Sessler DI, Lenhardt R: Perioperative normothermia to reduce the incidence of surgical-wound infection and shorten hospitalization. N Engl J Med 334:1209-1215, 1996

3. Sessler DI: Perioperative heat balance. Anesthesiology 92: 578-596, 2000
4. Rajagopalan $\mathrm{S}$, Mascha E, Na J, et al: Effects of mild perioperative hypothermia on blood loss and transfusion requirement. Anesthesiology 108:71-77, 2008

5. Seamon MJ, Wobb J, Gayghan JP, et al: The effects of intraoperative hypothermia on surgical site infection: An analysis of 524 trauma laparotomies. Ann Surg 255:789-795, 2012 
6. Frank SM, Fleisher LA, Breslow MJ, et al: Perioperative maintenance of normothermia reduces the incidence of morbid cardiac events. A randomized clinical trial. JAMA 277:1127-1134, 1997

7. Lenhardt R, Marker E, Goll V, et al: Mild intraoperative hypothermia prolongs postanesthetic recovery. Anesthesiology 87: 1318-1323, 1997

8. Karalapillai D, Story DA, Calzavacca P, et al: Inadvertent hypothermia and mortality in postoperative intensive care patients: Retrospective audit of 5050 patients. Anaesthesia 64:968-972, 2009

9. Billeter AT, Hohmann SF, Druen D, et al: Unintentional perioperative hypothermia is associated with severe complications and high mortality in elective operations. Surgery 156:1245-1252, 2014

10. Larach MG, Brandom BW, Allen GC, et al: Malignant hyperthermia deaths related to inadequate temperature monitoring, 20072012: A report from the North American malignant hyperthermia registry of the malignant hyperthermia association of the United States. Anesth Analg 119:1359-1366, 2014

11. Webb CAJ, Weyker PD, Moitra VK, et al: An overview of cytoreductive surgery and hyperthermic intraperitoneal chemoperfusion for the anesthesiologists. Anesth Analg 116:924-931, 2013

12. Grigore AM, Murray CF, Ramakrishna H, et al: A core review of temperature regimens and neuroprotection during cardiopulmonary bypass: Does rewarming rate matter? Anesth Analg 109:1741-1751, 2009

13. Sessler DI: Temperature monitoring and perioperative thermoregulation. Anesthesiology 109:318-338, 2008

14. Fox RH, Solman AJ: A new technique for monitoring the deep body temperature in man from the intact skin surface. J Physiol 212: 8-10, 1971

15. Fox RH, Solman AJ, Isaacs R, et al: A new method for monitoring deep body temperature from the skin surface. Clin Sci 44: 81-86, 1973

16. Singer B, Lipton B: Monitoring of core temperature through the skin: A comparison with esophageal and tympanic temperatures. Bull N Y Acad Med 51:947-952, 1975

17. Kobayashi T, Nemoto T, Kamiya A, et al: Improvement of deep body thermometer for man. Ann Biomed Eng 3:181-188, 1975

18. Togawa T: Non-invasive deep body temperature measurement. In: Rolfe P (ed). Non-invasive physiological measurements. London, Academic Press, 1979, pp. 261-277

19. Yamakage M, Iwasaki S, Namiki A: Evaluation of a newly developed monitor of deep body temperature. J Anesth 16:354-357, 2002

20. Togawa $T$, Nemoto $T$, Tsuji $T$, et al: Deep temperature monitoring in intensive care. Resuscitation 7:53-57, 1979

21. Lees DE, Kim YD, Macnamara TE: Noninvasive determination of core temperature during anesthesia. South Med J 73:1322-1324, 1980
22. Muravchick S: Deep body thermometry during general anesthesia. Anesthesiology 58:271-274, 1983

23. Langham GE, Maheshwari A, Contrera K, et al: Noninvasive temperature monitoring in postanesthesia care units. Anesthesiology 111:90-96, 2009

24. 3M: SpotOn temperature monitoring system model 370, operator's manual. Available at: http://multimedia.3m.com $/ \mathrm{mws} / \mathrm{media} /$ 8798030/operators-manual-english.pdf. Accessed April 16, 2016.

25. Bland JM, Altman DG: Agreement between methods of measurement with multiple observations per individual. J Biopharm Stat 17: 571-582, 2007

26. Machowiak PA, Wasserman SS, Levine MM: A critical appraisal of 98.6 degrees $\mathrm{F}$ upper limit of the normal body temperature, and other legacies of Carl Reinhold August Wunderlich. JAMA 268:1578-1580, 1992

27. Matsukawa T, Sessler DI, Ozaki M, et al: Comparison of distal oesophageal temperature with "deep" and tracheal temperatures. Can J Anaesth 44:433-438, 1997

28. Matsukawa T, Ozaki M, Sessler DI, et al: Accuracy and precision of "deep sternal" and tracheal temperatures at high- and low-fresh-gas flows. Br J Anaesth 81:171-175, 1998

29. Iden $\mathrm{T}$, Horn EP, Bein $\mathrm{B}$, et al: Intraoperative temperature monitoring with zero heat flux technology (3M SpotOn sensor) in comparison with sublingual and nasopharyngeal temperature. Eur J Anaesthesiol 32:387-391, 2015

30. Eshraghi Y, Nasr V, Parra-Sanchez I, et al: An evaluation of a zero-heat-flux cutaneous thermometer in cardiac surgical patients. Anesth Analg 119:543-549, 2014

31. Akata T, Yamaura K, Kandabashi $\mathrm{T}$, et al: Changes in body temperature during profound hypothermic cardiopulmonary bypass in adult patients undergoing aortic arch reconstruction. J Anesth 18: 73-81, 2004

32. Akata T, Setoguchi H, Shirozu K, et al: Reliability of temperatures measured at standard monitoring sites as an index of brain temperature during deep hypothermic cardiopulmonary bypass conducted for thoracic aortic reconstruction. J Thorac Cardiovasc Surg 133:1559-1565, 2007

33. Brandes IF, Perl T, Bauer M, et al: Evaluation of a novel noninvasive continuous core temperature measurement system with a zero heat flux sensor using manikin of the human body. Biomed Tech (Berl) 60:1-9, 2015

34. Sato H, Yamakage M, Okuyama K, et al: Urinary bladder and oesophageal temperatures correlate better in patients with high rather than low urinary flow rates during non-cardiac surgery. Eur J Anaesthesiol 25:805-809, 2008 